\title{
Changing the Landscape of an Urban Public Mental Health System: The 2008 New York State/New York City Mental Health-Criminal Justice Review Panel
}

\author{
Thomas E. Smith and Lloyd I. Sederer
}

In 2007 to 2008, there were several incidents of violence in New York City (NYC) involving individuals with serious mental illness. Some were dramatic and shocking; all were life-threatening or fatal, and subsequent media coverage and public outcry escalated with calls for a return to greater coercion and institutionalization of people with mental illness. Then New York State (NYS) Governor Eliot Spitzer informed the press there would be an investigation of these events.

Governor Spitzer and NYC Mayor Michael Bloomberg called for relevant state and city agency heads and experts to review the incidents of violence and provide recommendations about what might limit future similar incidents. In all, a dozen agencies were convened with a 90-day time frame to produce their report. A list of the members of the panel is included in its report ${ }^{1}$ (available at: http://www.omh.state.ny.us/ omhweb/justice_ panel_report/). The panel was chaired by Michael F. Hogan, PhD (Commissioner, NYS Office of Mental Health), Linda I. Gibbs (NYC Deputy Mayor for Health and Human Services), Denise E. O'Donnell (NYS Commissioner for Criminal Justice), and John Feinblatt (NYC Criminal Justice Coordinator).

Circumstances like these place enormous demand on public health and safety officials. Diverse stakeholders insist upon immediate action and often have conflicting agendas. Elected officials may support needed action but may lack the resources to realize their aims. Public health and mental health leadership need to represent scientific evidence in the face of emotionally charged claims. Criminal justice leadership needs to ensure the public safety. Critical decisions with far-reaching implications can be made on short notice, with limited time for consultation and deliberation before issuing a public document with meaningful and actionable recommendations.

These situations represent unique, if tragic, opportunities for significant social service system improvement and reform. ${ }^{2}$ The following "case history" describes how NYS and NYC public mental health leaders organized information, experts, and resources to create panel recommendations specific to mental health that established new policies, avoided ineffective escalations in coercive interventions, clarified longstanding regulations, and created a new service to enhance accountability and coordination of services for NYC's most vulnerable mentally ill individuals.

\section{THE NEW YORK STATE/NEW YORK CITY MENTAL HEALTH- CRIMINAL JUSTICE REPORT}

A panel of 41 individuals representing state and city agencies met over a 3-month period and delivered its report in May 2008. Experts were brought in to brief the

Smith and Sederer are with the New York State Office of Mental Health, New York, NY, USA.

Correspondence: Thomas E. Smith, New York State Office of Mental Health, New York, NY, USA. (E-mail: tes2001@columbia.edu) 
group regarding what is known about violence and mental illness. Several incidents of violence involving individuals with serious mental illness were reviewed in great detail.

The final panel report emphasized that, while uncommon, violence in individuals with serious mental illness should not be thought of as random. All of the individuals involved in the violent episodes, either as perpetrators or victims, had a significant history of contact with the public mental health system and had received intensive community- and hospital-based services. There was a common theme of dropping out of treatment with reduced monitoring and fewer services during extended periods of illness, resulting in clinical deterioration that led to repeated contacts, especially with emergency mental health and medical systems of care. Moreover, the incidents of violence occurred typically months to a year after an individual discontinued treatment. In other words, there was clear, observable evidence of individuals needing ongoing help and not receiving it, in spite of the vast network of services within the NYC public mental health system. All these individuals, in their own ways, communicated the need for help, as did some of their family members, but the safety net did not effectively respond.

The panel review and findings underlined issues that the public mental health leadership had long been aware of, thus presenting an opportunity to recommend needed improvements in NYC's public mental health system. The panel's recommendations were promptly accepted by the governor and mayor. Below, we describe elements of the report that represent new policy initiatives; regulatory clarifications; and the creation of a new oversight initiative.

\section{NEW POLICY: STANDARDS OF CARE FOR COMMUNITY MENTAL HEALTH CLINICS}

The cases reviewed by the panel revealed that basic quality standards for mental healthcare were not being consistently met throughout the NYC public mental health system. An examination of NYS regulations regarding clinic care (done in parallel to the panel work) revealed very brief and general regulatory requirements. These did not explicate what would be basic quality standards of care for matters such as initial evaluation, risk assessment, coordination of care, engagement of and outreach to patients, communication with families and other caregivers, detection of co-occurring health and substance use problems, and supervision of clinical personnel.

The NYS Office of Mental Health (OMH) consequently drafted standards of mental health clinic care that became a part of the panel report as interpretative guidelines for the existing regulations. Examples of areas addressed by the standards include: the timeliness of psychiatric evaluations; documentation of risk assessments; the importance of involving family and support persons in treatment; and the need for care review and outreach procedures when individuals experience lapses in care. The standards also cover administrative practices such as review of caseload assignments and supervision expectations for new and inexperienced staff.

To add gravitas, OMH determined to use the standards as key anchors in its licensing reviews for all mental health clinics (which require an $\mathrm{OMH}$ license to operate). OMH has developed, borrowing from The Joint Commission, a "tracer methodology" that will be implemented in January 2010 for all clinics scheduled for licensing renewal. The Standards of Care will serve as a template to guide reviewers' 
activities when they visit clinics. Traditional survey practices focused on review of human resources policies, staffing patterns, and environmental surveys; surveyors will now "trace" the care of individual clients, using the new standards of care to identify problems and processes that providers may need to redesign in order to improve the quality of their services. The tracer process will weigh, based on specific clients, a clinic's fidelity to these standards of care. In other words, clinic licenses will be contingent on meeting these standards.

\section{REGULATORY CLARIFICATION: INTEGRATION OF SERVICES}

The panel was briefed by experts on violence and mental illness, who described extensive research showing that individuals with co-occurring serious mental illness and substance abuse problems are the greatest risk for violence. ${ }^{3-7}$ Clinical studies demonstrate poor outcomes, including discontinuing treatment and violent episodes, in this population. ${ }^{8-10}$ The panel supported measures underway throughout the state by OMH and the NYS Office of Alcohol and Substance Abuse Services (OASAS) for mental health and substance abuse clinics to institute screening and assessment for co-occurring disorders and to link these to evidence based integrated dual diagnosis treatment. ${ }^{11,12}$

Traditional interpretations, misinterpretations, and folklore regarding NYS regulatory standards for OMH and OASAS needed remedy. When a mental health or substance abuse service provider was licensed by one or the other agency, there was a view that the co-occurring disorder could not be treated: for example, if a provider had a substance abuse license, it presumed that it was not authorized to provide mental health services. The same presumption held true for mental health providers, conversely. Since payment for services is dependent upon regulatory compliance, providers stayed in their own silos lest they violate any regulation, leaving clients adrift between two service systems and often not seeking services in either. This situation is not unique to NYS - the National Comorbidity Survey (NCS) found that only $40 \%$ of individuals with serious mental illness and cooccurring substance abuse accessed care, ${ }^{13}$ and findings from the NCS-Replication showed that among those receiving care, only $25 \%$ received some form of treatment for both their mental illness and substance abuse. ${ }^{14}$ Further data from NCS suggested that only $15 \%$ of individuals with serious mental illness received minimally adequate treatment. ${ }^{15}$

Concurrent with the Panel's work, senior staff from OMH and OASAS reviewed their respective licensure and regulatory guidelines and issued clarifications and Frequently Asked Questions (available at: http://www.oasas.state.ny.us/pio/ collaborate/documents/co-occurring.pdf). These publications declared that an individual with co-occurring mental illness and substance abuse problems could and should receive services for both conditions by the same provider agency, regardless of whether that provider is licensed by the OMH or OASAS. These guidelines were reviewed with providers at a series of statewide forums in the fall of 2008 .

Several other changes were made to augment these regulatory clarifications. New financing mechanisms, due to be in place in 2010, will allow NYS providers to bill for more than one service in the same day, further supporting integrated treatment for co-occurring disorders. The New York State Health Foundation, in collaboration with OMH and OASAS, funded a 4-year grant to support a cooccurring center of excellence to provide technical assistance to providers regarding 
integrated care. Finally, both agencies allocated funding to develop a series of over 40 training modules that will be delivered through "distance learning” techniques with the collaboration of Columbia and Dartmouth Universities. The technical assistance and training will not only provide concrete resources but also further underscore the intent of the state regulatory agencies to create real system-wide change.

\section{NEW SERVICES: THE NYC MENTAL HEALTH CARE MONITORING INITIATIVE}

A primary finding of the panel was that NYC's public mental health system is fragmented and coordination of care is often problematic when multiple providers serve the same client, at the same time or over time. There are problems with communication, treatment planning, collaboration amongst providers as well as with families, and accountability regarding who does what and when-especially with complex and highly unstable individuals. Too often, these high-need individuals disengage and drift away from care. Mental health providers vary in their response when clients do not keep appointments or do not pick up needed medications. Some misunderstand medicolegal liability and some eschew clients with histories of substance use, violence, or time spent in jail, prison, or forensic hospitals. Crises encountered with these individuals tax provider resources, especially those with primarily office-based services.

The combination of the dramatic, violent events reviewed by the panel, the highprofile media coverage, and the committed awareness of the governor and mayor created a unique opportunity for significant action on the part of the panel and its constituent agencies. The system-wide problems described in the panel report are not new. We know that care management works, especially when combined with outreach and integrated treatment. ${ }^{16-21}$ The panel recommendations thus were tailored towards changes that would lead to enhanced care coordination.

One key result was that the panel recommended the establishment of a "Care Monitoring" initiative to serve individuals with serious mental illness who are at highest risk for discontinuing services and experiencing poor outcomes. Treatment works: the evidence from experts and established clinicians is clear that the best way to serve high-need individuals with psychotic illness and substance abuse and to serve the public safety is to engage and retain these people in evidence-based care for their psychotic and substance use disorders. The creation of Care Monitoring teams, jointly run by OMH and the NYC Department of Health and Mental Hygiene, will alert and assist providers in identifying those disengaging from services and support outreach strategies to reengage and sustain these vulnerable individuals in care.

The panel also recommended that these care monitoring activities be datadriven. The panel review process was informed by detailed case reviews of those individuals involved in specific instances of violence supplemented with Medicaid claims and other state administrative data. The case reviews demonstrated lengthy courses of illness and repeated glancing exchanges with the health, mental health, and criminal justice systems. The amount and breadth of data available in these databases were notable, revealing that current information technology capabilities are advanced enough such that these data could be used to guide real-time clinical decision-making. Consequently, the panel strongly recommended that the care monitoring teams incorporate a data monitoring system into their work. 
The acceptance of the panel report and recommendations by the governor and mayor set the stage for aligning the needs of high-need individuals with public safety officials, families, and patient care advocates. Since the adoption of the report, a NYC Mental Health Care Monitoring Initiative was conceptualized, and its implementation funded and planned. In this initiative, groups of individuals with serious mental illness and histories of high intensity services will be identified from Medicaid and other data sources on a monthly basis. Examples include individuals who have been under courtmandated outpatient treatment or those receiving Assertive Community Treatment or case management services. The project will also identify individuals with a history of serious mental illness and criminal justice involvement, as well as those with frequent psychiatric hospitalizations or emergency room visits. Pilot work suggested that at any point in time, over 20,000 individuals city-wide meet high-need criteria and qualify to have their patterns of care monitored using Medicaid and other databases. Notification flags were then defined to identify individuals within this high-need group who may be experiencing a lapse in care. Examples of flags include:

- No psychiatric medication prescriptions filled in the prior 60 days;

- No community-based mental health services received in the prior 120 days; and

- Two or more psychiatric emergency room or inpatient hospitalizations in the prior 120 days.

Field trials done in the spring of 2009 revealed that several thousand individuals will meet one or more of these notification flags in any given month. The Care Monitoring initiative will have borough-based care monitoring teams of clinical staff to alert and consult with local providers. Providers will be contacted and asked if the notification flags reflect that the individual identified by the care monitoring team is at risk for a treatment lapse or instead is a "false positive." When there is agreement that the individual has experienced a lapse in care, the Care Monitoring team staff will discuss and collaborate with providers regarding needed outreach efforts and reengagement strategies.

The NYC Care Monitoring Initiative is a new and, to our knowledge, unprecedented large-scale public agency service that aims to improve high-need population-based care with clinically informed, data-driven management processes. The cost to hire and staff the teams is being shared jointly by the $\mathrm{OMH}$ and the NYC Department of Health and Mental Hygiene. The project launches in Brooklyn (30\% of New York City population) in September 2009, with a plan to implement city-wide by July 2011.

\section{CONCLUSIONS}

This commentary describes current efforts by the NYS and NYC mental health leadership to address critical problems with mental illness, substance abuse, and violence. The 2008 New York State/New York City Criminal Justice Review Panel made a range of recommendations involving clarification of regulatory guidelines, enhancement of existing standards, and a new care monitoring service. Many questions remain, including how to define and establish optimal outreach and reengagement strategies for high-need individuals with serious mental illness. The Care Monitoring teams will focus on this and related issues and use what is learned to improve the delivery of city-wide services. This initiative, along with the other 
changes made following the panel report, represent a successful case study for the development of evidence-based policy.

\section{REFERENCES}

1. Hogan MF, Gibbs LI, O'Donnell DE, Feinblatt J. New York State/New York City Mental Health-Criminal Justice Panel Report and Recommendations. New York: New York State Office of Mental Health; 2008.

2. Hogan MF, Sederer LI. Mental health crises and public policy: opportunities for change? Health Aff (Millwood). 2009; 28(3): 805-808.

3. Elbogen EB, Johnson SC. The intricate link between violence and mental disorder: results from the national epidemiologic survey on alcohol and related conditions. Arch Gen Psychiatry. 2009; 66(2): 152-161.

4. Fazel S, Langstrom N, Hjern A, Grann M, Lichtenstein P. Schizophrenia, substance abuse, and violent crime. JAMA. 2009; 301(19): 2016-2023.

5. Monahan J. The MacArthur studies of violence risk. Criminal Behav Ment Health. 2002; 12: S67-S72.

6. Swanson JW, Holzer CE, Ganju VK, Jono RT. Violence and psychiatric disorder in the community: evidence from the Epidemiologic Catchment Area surveys. Hosp Community Psychiatry. 1990; 41(7): 761-770.

7. Arseneault L, Moffitt TE, Caspi A, Taylor PJ, Silva PA. Mental disorders and violence in a total birth cohort: results from the Dunedin Study. Arch Gen Psychiatry. 2000; 57(10): 979-986.

8. Ascher-Svanum H, Faries D, Zhu B, Ernst FR, Swartz MS, Swanson JW. Medication adherence and long-term functional outcomes in the treatment of schizophrenia in usual care. J Clin Psychiatry. 2006; 67(3): 453-460.

9. Swartz MS, Swanson JW, Hiday VA, Borum R, Wagner HR, Burns BJ. Violence and severe mental illness: the effects of substance abuse and nonadherence to medication. Am J Psychiatry. 1998; 155(2): 226-231.

10. Wallace C, Mullen PE, Burgess P. Criminal offending in schizophrenia over a 25 -year period marked by deinstitutionalization and increasing prevalence of comorbid substance use disorders. Am J Psychiatry. 2004; 161(4): 716-727.

11. Drake RE, O'Neal EL, Wallach MA. A systematic review of psychosocial research on psychosocial interventions for people with co-occurring severe mental and substance use disorders. J Subst Abuse Treat. 2008; 34(1): 123-138.

12. Green AI, Drake RE, Brunette MF, Noordsy DL. Schizophrenia and co-occurring substance use disorder. Am J Psychiatry. 2007; 164(3): 402-408.

13. Kessler RC, Nelson CB, McGonagle KA, Edlund MJ, Frank RG, Leaf PJ. The epidemiology of co-occurring addictive and mental disorders: implications for prevention and service utilization. Am J Orthopsychiatry. 1996; 66(1): 17-31.

14. O'Brien CP, Charney DS, Lewis L, et al. Priority actions to improve the care of persons with co-occurring substance abuse and other mental disorders: a call to action. Biol Psychiatry. 2004; 56(10): 703-713.

15. Wang PS, Demler O, Kessler RC. Adequacy of treatment for serious mental illness in the United States. Am J Public Health. 2002; 92(1): 92-98.

16. Pincus HA, Houtsinger JK, Bachman J, Keyser D. Depression in primary care: bringing behavioral health care into the mainstream. Health Aff (Millwood). 2005; 24(1): 271276.

17. Bodenheimer T. Coordinating care-a perilous journey through the health care system. $N$ Engl J Med. 2008; 358(10): 1064-1071.

18. Rosenthal TC. The Medical Home: growing evidence to support a new approach to primary care. J Am Board Fam Med. 2008; 21(5): 427-440.

19. Smith TE, Sederer LI. A new kind of homelessness for individuals with serious mental illness? The need for a "mental health home". Psychiatr Serv. 2009; 60(4): 528-533. 
20. Horvitz-Lennon M, Kilbourne AM, Pincus HA. From silos to bridges: meeting the general health care needs of adults with severe mental illnesses. Health Aff (Millwood). 2006; 25 (3): 659-669.

21. American Public Human Services Association, National Association of State Medicaid Directors. Serving the Needs of Medicaid Enrollees with Integrated Behavioral Health Services in Safety Net Primary Care Settings. Washington: National Association of State Medicaid Directors; 2008. 